\title{
The Relationship Between Self-Regulations and Online Learning in an ESL Blended Learning Context
}

\author{
Hind Al Fadda ${ }^{1}$ \\ ${ }^{1}$ Curriculum and instruction, college of education, King Saud University, Riyadh, Saudi Arabia \\ Correspondence: Hind Al Fadda, Curriculum and instruction, college of education, King Saud University, \\ Riyadh, Saudi Arabia
}

Received: February 28, 2019

Accepted: May 9, 2019 Online Published: May 11, 2019

doi: 10.5539/elt.v12n6p87

URL: https://doi.org/10.5539/elt.v12n6p87

\begin{abstract}
Technology has changed the social landscape and the nature of social interaction. Education has been affected by these changes, as technology has facilitated the creation and Implementation of new educational environments and delivery methods (e.g., distance and blended-learning structures). While the prevalence of such approaches has increased over time, little is known about the learning skills that promote academic success; consequently, the ability of instructors and administrators to implement appropriate methods to foster these skills is hindered. This study examines distance education and focuses on the self-regulation literature to identify skills that can predict ESL learning success in a blended educational environment. Data were collected from 70 students attending a blended English language course. Using subscales from Motivated Strategies for Learning Questionnaire, five Self-regulatory attributes likely to predict academic performance were identified: intrinsic goal orientation, self-efficacy for learning and performance, time and study environment management, help seeking, and Internet self-efficacy.
\end{abstract}

Keywords: ESL, blended learning, motivation, study skills

\section{Introduction}

Innovations in computer technology have been linked to changes in ESL course structures. Nevertheless, these innovations have generally supplemented rather than replaced traditional face-to-face lectures. Research has concentrated on distinctive kinds of computer use, such as computer-based composition, hypermedia (i.e., graphics, audio, video, plain text, and hyperlinks). Additionally, attention has focused on synchronous and offbeat computer mediated communication (CMC), such as online group chats and instant messaging, respectively. Studies concerning the benefits of integrating CMC into technology- enhanced academic courses have revealed conflicting results. Researchers such as Sullivan and Pratt (1996) and Warschauer $(1996,1998)$ reported that $\mathrm{CMC}$ integration encouraged correspondence, decreased uneasiness, advanced agreeable learning and birthed new and innovative class structures. In contrast, Braine $(1997,2001)$ noted that CMC did not significantly enhance composition skills or learning. Regarding the perception of undergraduates toward CMC, Hirvela (2007) and Boyd (2008) found a mixture of both fulfillment and disillusion among students.

Prior research concerning the implementation of technology in academic learning structures has primarily focused on computers as supplementary tools in classroom- based courses and their effect on academic performance. As such, most of these studies are atheoretical in nature, and focus on group academic outcomes, descriptions of distance education programs, and comparative evaluations between distance and face-to-face courses. Emphasis has also been placed on learner traits and on matching those traits with media variables. While these aforementioned areas are helpful in understanding technology's impact on academic practice, they are ineffective at identifying the relevant theoretical underpinning: consequently, they cannot advance teaching and learning theories in a manner that can benefit distance learners or distance instructors This study examines distance education with a focus on the self-regulation literature. Data were collected from 70 students attending a blended undergraduate English language course at the Saudi Electronic University in Riyadh, Saudi Arabia. Using subscales from the motivated strategies for learning Questionnaire (MSLQ), we attempt to identify the self-regulatory attributes that are likely to predict academic performance in a blended educational environment. 


\section{Background}

\subsection{About ESL}

ESL programs offer academic courses that afford students an opportunity to work with bilingual instructors in order to learn English, and provide students numerous benefits regardless of their ability. In that respect, both fledgling and advanced learners can enhance their English proficiencies by participating in such programs. Online ESL courses likewise allow administrators to reach diverse regions of the world, making exceptional English training and learning possible around the world. As the economy has become increasingly globalized, national boundaries have started to blur, and English is currently the main language used in the management of international organizations. Consequently, English is vital to anyone who wishes to keep pace with a constantly evolving global society.

ESL classes are capable of doing more than merely helping students to master a language's fundamentals, such as composition, conversation, and reading comprehension: Such classes can also assist students in improving their inflection and enunciation when speaking, which should ensure that others can comprehend them. Furthermore, online TESOL accreditation can familiarize students with English-speaking societies, and subsequently enable them to grasp culturally specific references to which they may not ordinarily be exposed. These exchanges can also aid learners in becoming better writers. Conducting business, especially on a global scale, may require one to learn English. Indeed, international business and organizations generally require their employees to possess at least a basic familiarity with English. For example, the tourism and hospitality industry often seeks workers who can communicate competently in English: such individuals may find well-paying jobs at the popular hotels and resorts that are frequented by vacationers from countries such as the United States, Canada, and Britain. Translation also offers lucrative jobs opportunities to those who have mastered English as a foreign language. Moreover, native speakers of English can secure employment as ESL coaches and use their skills to find employment abroad.

Learning English allows one to access vast amounts of data that are not available in any other language. Academic works and journals are generally published first in English before being translated into other languages. Furthermore, many non-native English- speaking students decide to attend schools in English-speaking nations due to the exceptional quality of education they offer, in addition to the opportunities to increase their English proficiency through immersion.

Learning to speak, read, and write in English is a prerequisite for functioning in English-speaking societies. Many non-English speaking nations throughout Asia, Europe and Latin America require students to attend ESL classes at the primary and secondary school levels. These countries deem such actions necessary because English is the language of international trade. Students in such countries who complete their schooling with a grasp of English have more employment opportunities available to them, and their mastery of English consequently aids their respective nations in becoming more economically competitive. Saudi Arabia is no exception to this phenomenon, and it embraces and understands the importance of learning and using the English Language.

Web-assisted or blended learning has recently gained a great deal of attention among ESL-researchers and instructors worldwide. For the purpose of this study, blended learning involves a combination of computer-based distance education and traditional face- to-face learning. This new approach shifts the focus of ESL education away from restricted and repetitive delivery methods to a more dynamic and socially intuitive learning procedure that emphasizes collaboration in the language acquisition process. Through blended learning, students do not merely learn by memorizing vocabulary words or grammar rules, but from collaboration and dynamic support. Furthermore, online education promotes autonomous learning and provides students with an authentic learning experience that exceeds what their instructors alone are capable of offering. When students communicate in virtual learning groups they participate in a more socially and culturally authentic environment, which enables them to more effectively acquire and comprehend vocabulary words and linguistic structures.

ESL learning in a blended environment affords students access to various resources that can promote interest in language learning and increase listening proficiency. Similarly, the utilization of blogs, wikis, and web searches can lead to increased written English proficiency. Software that facilitates teleconferencing and long-distance group collaboration, such as Skype, allows learners to enhance their listening and speaking skills while communicating with native speakers regardless of their location. Such blended learning environments also help students gain cross-cultural awareness, which in turn promotes language learning. These exchanges can be mediated by an instructor, occur between groups of non-native speakers, or between native and non-native speakers.

The potential for web-enhanced curriculums and blended learning to promote The English language has been 
discussed by scholars and academics worldwide. The versatility afforded by computers and the Internet enables students to attend English Lessons in virtual classrooms. Additionally, learners can expand their use of English through online interaction, which should consequently increase test scores, at least among some students.

Blended learning can help students to become more autonomous learners. Indeed, web-based ESL instruction in a blended learning environment gives students increased control over their learning, thus lessening their dependence on instructors. Despite this lessened dependence on instructors, blended learning still allows teachers to provide support by means of traditional face-to-face instruction. Based on the innovative solutions that blended-learning offers, it is likely to become a foundation for English language instruction worldwide.

\subsection{Literature Review and Theoretical Framework}

Numerous studies have examined the impact of traditional face-to-face ESL classroom instruction and the integration of synchronous CMC on learner interest and accomplishment. Researchers such as Sullivan and Pratt (1996) and Warschauer (1996) have emphasized the importance of CMC in classrooms. Nevertheless, a need exists to identify learner characteristics that facilitate success in blended learning environments, which is particularly important given the increasing prevalence of blended ESL courses.

Many research efforts have adopted Moore's transactional distance theory as a descriptive framework for understanding distance education programs and their effects (Braine $(1997,2001)$. The three primary descriptive variables comprising Moore's theory are interaction (dialogue), structure, and autonomy. These three variables are assumed to be interrelated and typical of all distance learning programs and courses. However, the present study is primarily concerned with examining autonomy.

According to Zimmerman (2001), autonomous (or self-regulated) learners are behaviorally, motivationally, and meta-cognitively active in accomplishing their academic and learning goals. Furthermore, they are guided by task-specific learning goals and attempt to monitor their progress: such individuals are self-motivated and capable of learning even in the midst of abnormal levels of distraction (Hirvela, 2007). Likewise, Boyd (2008) asserts that autonomous learners are adaptive and capable of controlling the key aspects of their behavior, cognition, and environment that are related to their learning goals. Zimmerman (2001) further argues that learner's personal choices, and the control that they exert, are the defining aspects of learner autonomy, and as such play a critical role in distance education. Moreover, a correlation exists between self-regulation and lifelong learning skills.

Five self-regulatory attributes were identified based on a review of the prior literature that we believe are particularly important for successful distance learning: motivation, self- management, and learning assistance management. Descriptions for each of these attributes are provided in Table 1.

Table 1. Self-regulatory attributes related to online learner autonomy

\begin{tabular}{ll}
\hline Self - Regulatory Attribute & Psychological Process \\
\hline Motivation & $\begin{array}{l}\text { Beliefs related to one's perceived ability to perform } \\
\text { learning tasks successfully, as well as goal-setting to } \\
\text { determine why a learner wishes to engage in such } \\
\text { tasks. } \\
\text { The degree of confidence a learner possesses when } \\
\text { using learning technologies that are common in online } \\
\text { education. }\end{array}$ \\
Experience with Internet Technology & $\begin{array}{l}\text { One's ability to manage and structure learning in a } \\
\text { manner that is timely, effective, and productive. }\end{array}$ \\
Time Management Skills & $\begin{array}{l}\text { One's ability to ensure that his/her study environment } \\
\text { is conducive to learning. }\end{array}$ \\
The ability to know when assistance is needed, locate \\
Telp-seeking Skills
\end{tabular}

The attributes above have been cited in the self-regulation literature as critical factors that affect learning in 
traditional classrooms; moreover, these attributes have also been cited in the literature pertaining to distance education as components that profoundly affect learning achievement. Therefore, the present research seeks to determine whether these attributes also play a critical role as significant predictors of academic achievement and success in blended learning environments (Lantolf \& Pavlenko, 2001).

It is worth noting that these are not the only variables that can possibly affect self-regulatory behavior, but those that have been selected for examination due to their prominence in the literature concerning distance education (Leont'ev, 1981). Other self- regulatory attributes that take both behavioral and motivational forms also contribute to self- regulated behavior, and it is highly probable that these attributes also facilitate successful blended learning (Armstrong, 2011)

\section{Methods}

\subsection{Participants}

The research participants $(\mathrm{n}=70)$ were students attending a blended undergraduate course at the Saudi Electronic University in Riyadh, Saudi Arabia. Each course consisted of eight sections, of which three employed online learning. The students were free to select whether they wished to register in a blended or traditional section. Seventy- five percent of the class time in blended courses was devoted to online activities, while $25 \%$ Involved traditional face-to-face activities, although the instructor of each respective section was ultimately responsible for determining these percentages.

The participants in the sample ranged in age between 18-41 years old $(\mathrm{m}=20.6)$, and comprised 35 males and 35 females. Thirty-four (48.9\%) of the participants majored in Computer Science, 10 (14.9\%) Leadership, 7 (10.6\%) Health Informatics, 4 (6.4\%) General Law, and 13 (19.1\%) Economics (see Figure 1). Twenty-eight (40.5\%), 29 $(41.5 \%)$ and $13(18.1 \%)$ of the students were sophomores, juniors, and seniors respectively.

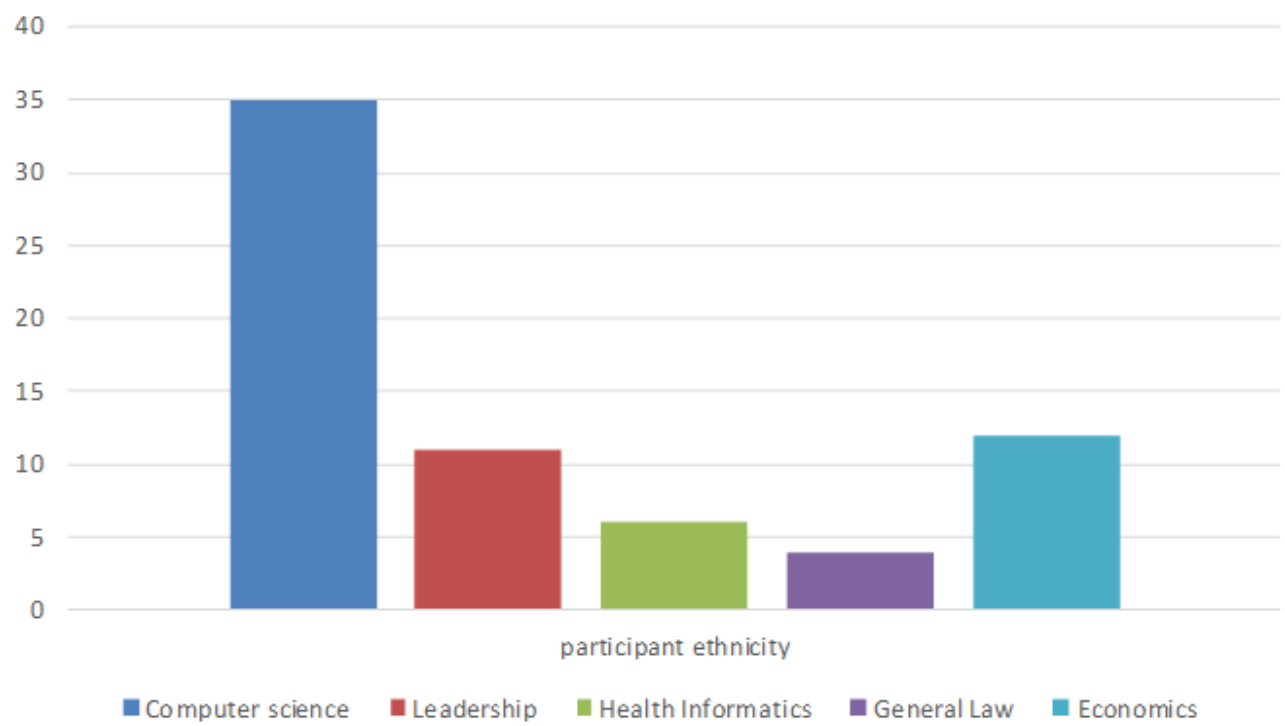

Figure 1. Number of participants according to major

\subsection{Instruments}

The criterion variable was students' online academic performance, which was determined by calculating their final grades as a percentage. Based on the literature review, five self-regulatory predictor variables were selected due to their assumed effect on online blended learning performance: motivation (self-efficacy and goal orientation), time management, study environment management, learning assistance management, and Internet self-efficacy. The first four variables were measured according to relevant MSLQ subscales (Lantolf \& Thorne, 2006).

The MSLQ was developed over a period of three years in the 1980's and early 1990's during which it was validated through factor/reliability analyses and correlations with measures of achievement (Lantolf \& Genung, 2002). It contains 81 items that are divided into motivation and learning strategy sections. The motivation 
section comprises 31 items spread across six subscales: intrinsic goal orientation, extrinsic goal orientation, task value, control of learning beliefs, leaning/performance self-efficacy, and test anxiety. The learning strategy section contains 50 items spread across nine subscales: rehearsal, elaboration, organization, critical thinking, meta-cognitive self-regulation, time/study environment management, effort regulation, peer learning, and help-seeking. The MSLQ subscales selected for this study (with their reported alpha reliability coefficients) were intrinsic goal orientation (.74), self-efficacy for learning and performance (.93), time/study environment management (.76), and help-seeking (.52).

The eight-item Internet self-efficacy scale developed by Eastin and LaRose (2006) was used to measure self-efficacy, while confirmatory factor analysis was used to determine the scale's validity. Internet self-efficacy correlated positively with Internet usage, as well as prior Internet experience and outcome expectancies, which is in agreement with social cognitive theory. A negative correlation was found between Internet stress and selfdisparagement, although this finding was expected. Furthermore, Internet self-efficacy was determined to be unrelated to measures of general psychological well-being (Eastin \& LaRose, 2006). The alpha reliability coefficient of this scale was 93 .

\subsection{Procedure}

A nonexperimental correlational research design using nonrandom sampling was employed to determine the predictive value of the six independent variables in terms of the aforementioned criterion variable (final grades). Research questionnaires were distributed to students in the blended sections twice during the Spring and Fall of 2016. The students took the questionnaires home to complete, and those wishing to participate returned the completed questionnaires during the next on-campus session. Of the 352 Questionnaires distributed, 70 valid questionnaires were returned, representing an overall return rate of $19.89 \%$.

\section{Results}

The study employed both descriptive and inferential statistical analysis. The descriptive analysis contained an overview of the sample's demographics and the means, standard deviations, and simple correlations of the variables investigated. A reliability analysis of the subscales was also conducted. Inferential analysis was completed using SPSS Version 9.0 with stepwise multiple regression. The level of significance for the analyses was .05 .

Simple correlations of all of the variables revealed that self-efficacy for learning and performance/verbal ability correlated significantly with final grades $(\mathrm{r}=.29, \mathrm{p}<.01$ and $\mathrm{R}=.26, \mathrm{p}<.05$, respectively). The significant correlation between intrinsic goal orientation and self-efficacy $(r=.47, p<.01)$ reflected the relationship between them as motivational attributes. Furthermore, the significant correlation between time/study environment management with intrinsic goal orientation $(\mathrm{r}=.31, \mathrm{p}<.01)$ and self-efficacy $(\mathrm{r}=.32, \mathrm{p}<.01)$ indicated the relationship between learner motivation and the behavioral strategies involved in learner control of study time/environment. The minor negative correlations between help- seeking and Internet self-efficacy with final grades indicated that as grades increased, help- seeking and Internet self-efficacy marginally decreased.

Stepwise multiple regression analysis revealed that only self-efficacy for learning/performance and verbal ability significantly contributed to predicting variance in final grades $(\mathrm{R}$ square value $=.134$ : adjusted $\mathrm{R}$ square value $=.115: \mathrm{F} 2,91=7.06, \mathrm{p}<0.05)$. The semipartial correlations for each of the significant predictor variables were $\mathrm{r}(91)=.254, \mathrm{p}<.011$ and $\mathrm{r}(91)=.223, \mathrm{p}<.025$ for self -efficacy and verbal ability respectively. The semipartial correlation for self-efficacy squared was .07, indicating that self-efficacy accounted for $7 \%$ of the variance in final grades, with verbal ability held constant. The semi-partial correlation for verbal ability squared rendered a value of .05 , indicating that verbal ability accounted for $5 \%$ of the variance in final grades, with self-efficacy held constant. Therefore, self-efficacy and verbal ability together accounted for approximately $12 \%$ of the variance in the final grades. The other self-regulatory variables did not contribute significantly to the regression equation.

\section{Discussion and Pedagogical Implications}

The sample studied was most likely one in which self-regulation was not a problem area, as it was derived from a school with rigorous selection procedures. As such, the sample was probably highly self-regulated. The fact that the course modules were presented online likely influenced the results as well, since each module had a number of self-regulation-enhancing elements embedded within them, including focus topics and a reading guide.

The significant and positive relationship between verbal ability and performance (as represented by student's final grades) was expected. The primary and initial assumption was that verbal ability, as a measure of 
intelligence, would have a relatively significant and positive relationship with performance. This was true given the text-based nature of the course, which can be described as heavy.

The significant correlation between self-efficacy and final grades in this study supported existing research findings, which assert that a significant and positive relationship, either direct or indirect, exists between self-efficacy and performance in online education. Efficacy-enhancing activities and feedback should therefore be integrated into courses to assist students in the successful completion of courses.

The course's blended nature also likely contributed to the research findings, and may explain why help-seeking was not a significant predictor of final grades. Help- seeking was probably not an issue since students received regular feedback from class professors and lab instructors, in addition to other students, during on-campus meetings. Furthermore, the blended nature of the class could explain why time/study environment management and Internet self-efficacy were not significant predictors of performance, since frequent on-campus meetings diminished the need for independent study. Lastly, the lack of a significant relationship between Internet self-efficacy and academic performance could be partly explained by the blended nature of the class, since students were not entirely dependent on the Internet, thus lessening the importance of individual autonomy. Moreover, the Internet proficiency among those sampled may have been high.

In summary, this research found that intrinsic goal orientation, Internet self- Efficacy, help-seeking, and time/study environment management were not significant predictors of performance. A significant and positive correlation was found between self- efficacy and course grades, and between verbal ability and course grades. While correlation does not prove causality, it can indicate a possible pattern of influence between the two variables. In other words, self-efficacy and verbal ability may be significant predictors of performance in online, blended learning context. Nevertheless, further research is required to test this relationship.

\section{Conclusions and Further Research}

Further research should be conducted utilizing a sample from a less homogeneous population. For example, such research may use a sample from a community college where students study online is likely to exhibit a greater degree of individual variation regarding self-regulatory skills. Moreover, while age and gender were not factors in this study's research design, the investigation of such individual variables would be beneficial for determining their impact on self-regulation and online learning.

Values that are predictive of motivational components also merit further investigation, such as extrinsic motivation, control of learning beliefs, value beliefs, and affective factors. Learning strategies, including elaboration, critical thinking, effort regulation, and meta-cognitive self-regulation, should also be examined. Additionally, it would be prudent to conduct further research to determine which efficacy-enhancing interventions are most effective in an online context.

Finally, there is a need to determine whether any significant differences exist between self-regulatory attributes that function as contributing factors on performance among various types of online education. For example, one might make comparisons between blended and purely online courses, and between structured and less structured courses. With this in mind, it would be beneficial to investigate the various blended course structures being designed and implemented in higher education today. This might involve examining the numerous unique characteristics of various blended learning structures that employ a mixture of different technologies (e.g., face-to-face and online delivery of instructional material and content) and their impact on learner success.

\section{References}

Armstrong, D. A. (2011). Students' perceptions of online learning and instructional tools: A qualitative study of undergraduate students use of online tools. Turkish Online Journal of Educational Technology, 10(3), 222-226.

Boyd, P. W. (2008). Analyzing students' perceptions of their learning in online and hybrid first-year composition courses. Computers and Composition, 25(2), 224-243. https://doi.org/10.1016/j.compcom.2008.01.002

Braine, G. (1997). Beyond word processing: Networked computers in ESL writing classes. Computers and Composition, 14(1), 45-58. https://doi.org/10.1016/S8755-4615(97)90037-2

Braine, G. (2001). A study of English as a foreign language (EFL) writers on a local-area network (LAN) and in traditional classes. Computers and Composition, 18(3), 275-292. https://doi.org/10.1016/S87554615(01)00056-1

Eastin, M. S., \& LaRose, R. (2006). Internet self-efficacy and the psychology of the digital divide. Journal of Computer-Mediated Communication, 6(1), 323-335. https://doi.org/10.1111/j.1083-6101.2000.tb00110.x 
Hirvela, A. (2007). Computer-mediated communication and the linking of students, text, and author on an ESL writing course listserv. Computers and Composition, 24(1), 36-55. https://doi.org/10.1016/j.compcom. 2006.12.004

Lantolf, J. P., \& Genung, P. (2002). I'd rather switch than fight': An activity theoretic study of power, success and failure in a foreign language classroom. In C. Kramsch (Ed.), Language acquisition and language socialization: Ecological perspectives (pp. 175-196). London, UK: Continuum Press.

Lantolf, J. P., \& Pavlenko, A. (2001). (S)econd (1)anguage (a)ctivity: Understanding language learners as people. In M. Breen (Ed.), Learner contributions to language learning: New directions in research (pp. 141-158). London, UK: Longman.

Lantolf, J. P., \& Thorne, S. L. (2006). Sociocultural theory and the genesis of second language development. Oxford, UK: Oxford University Press.

Leont'ev, A. N. (1981). The problem of activity in psychology. In J. V. Wertsch (Ed.), The concept of activity in soviet psychology (pp. 37-71). Armonk, NY: Sharpe.

Sullivan, N., \& Pratt, E. (1996). A comparative study of two ESL writing environments: A computer-assisted classroom and a traditional oral classroom. System, 24(4), 491-501. https://doi.org/10.1016/S0346251X(96)00044-9

Warschauer, M. (1996). Comparing face-to-face and electronic communication in the second Language classroom. CALICO Journal, 13(2), 7-26.

Warschauer, M. (1998). Online learning in sociocultural context. Anthropology and Education Quarterly, 29(1), 68-88. https://doi.org/10.1525/aeq.1998.29.1.68

Zimmerman, B. J. (2001). Theories of self-regulated learning and academic achievement: An overview and analysis. In B. J. Zimmerman, \& D. H. Schunk (Eds.), Self-regulated learning and academic achievement: Theoretical perspectives (pp. 1-37). Mahwah, NJ: Erlbaum.

\section{Copyrights}

Copyright for this article is retained by the author(s), with first publication rights granted to the journal.

This is an open-access article distributed under the terms and conditions of the Creative Commons Attribution license (http://creativecommons.org/licenses/by/4.0/). 